\title{
Communication Barriers and Process of Feedback in Social Interactions
}

\author{
Ayesha Zahid ${ }^{1 *}$ (), Zhu Qinghe ${ }^{1}$ (), Ali Sohail $^{2}$ ()
}

${ }^{1}$ School of Journalism and Mass Communication, Shaanxi Normal University, Xian 710119, Shaanxi, CHINA

${ }^{2}$ School of Public Policy and Administration, Xi'an Jiaotong University, Xi'an, 710119, Shaanxi, CHINA

*Corresponding Author: ayesha@snnu.edu.cn

Citation: Zahid, A., Qinghe, Z., Sohail, A. (2021). Communication Barriers and Process of Feedback in Social Interactions. Mediterranean Journal of Social E Behavioral Research, 5(1), 3-12. https: //doi.org/10.30935/mjosbr/10804

\begin{abstract}
Feedback is an essential component of the communication process and without feedback, any communication is considered as incomplete. The research intended to explore the process of communication, its impeding factors and varying aspects of feedback in it. The study analyzed communication barriers involved in the family, educational and religious institutes in Pakistani society. The study also intended to explore various alternate sources for feedback developed by the message receiving audience due to different hindering aspects of social institutes. The current research applied a qualitative approach with the interview method. Keeping in view the objectives of the study, 60 respondents were selected through purposive sampling technique. Furthermore, three categories comprising students, children and religious followers, 20 each, from their respective social institutes, were derived through stratified sampling technique. The researcher found out the communication barriers; stereotypical believes, less awareness with modern knowledge, poor educational background and social pressure, to be the main reasons in diverting the receivers' feedback route from the standard pathway to alternate sources. Study apprehend that the message receiving audience, under specified communication barriers, relies on alternate sources, social discussion, internet social media and interpersonal communication to relieve their response. Resultantly, the response which supposedly had to reach the exact sender of the message, reaches the irrelevant audience in the society, making it more complicated and diverse. Hence, the process of communication gets diverted and results in the generation of new ways of feedback.
\end{abstract}

Keywords: communication barriers, feedback, social interactions, Pakistani family system

Received: 24 Jan. $2021 \bullet$ Accepted: 3 Mar. 2021

\section{INTRODUCTION}

Human communication is a social interaction process. It is an essential part of our daily life. It is a process of creating, exchanging, sharing ideas, information, opinions, facts, feelings, and experiences between a sender and a receiver. For effective learning and understanding, human beings must adopt effective communication, get information, exchange ideas and prompt feelings. Thus, communication is a procedure which emphasizes to transmit information and common understanding among individuals (Keyton, 2011). There is a variety of communication, such as verbal, nonverbal and oral communication. Due to verbal communication, a message or any information is transferred in word form. Nonverbal communication is a process in which a message or information can be transferred or conveyed in the form of a sign, body language, gestures and posture. Finally, which is called Oral communication speeches, lectures, demonstration presentations, assignments, discussions, negotiation and aspects can be present orally. (İssman, A., Dabaj, F., Altinay, F. \& Altinay, Z., 2003). To complete this process of communication feedback is very important if the sender is not considering the importance of feedback and keeps delivering the message it means the communication process has not been completed here. However, the various aspects of the communication process establish the value of interaction amongst the community. Consequently, the issues in any one of the aspects may lead to a reduction of communication success (Keyton, 2011). Hence, for instance, data must be programmed into a note that could be perceived as the transmitter targeted. Nevertheless, the choice of the specific means for the transmission of the message could be significant, since there are several options.

\section{COMMUNICATION BARRIERS}

Communication is a functional element of life. People are socialized through effective communication skills. Effectiveness of communication depends on to what extent effective the process of communication and learning, and up to what extent there are communication barriers among the public, which are stakeholders. It is 
essential because every activity of a person involves direct or indirect interaction. Communication assistance dramatically affects the organization's behavior on a person (Brun, 2010; Summers, 2010). On the other hand, deficiency of feedback communication slows down the organizational efficiency (Lutgen-Sandvik, 2010). That's why good communication skills play an important role in one's success as an administrator (Yate, 2009).

As a skillful communication passes among persons', different small and large group, industries and public private, different culture and races settings, that is why there is more exertion in overwhelming a greater diversity of barriers. The communication barriers exist in all organization and these barriers may be particular or environmental or noise and cultural differences, bias within the organization. Communication barriers are being increased or emerged in education as technologies are getting better or expansion in their capacities and scope throughout the world. Communication methods have been expanded with internet-capable devices and with this expansion, the opportunities for collaboration, context-aware problem solving and access to resources have also been increased (Donaldson, 2011).

\section{PROCESS OF FEEDBACK IN SOCIAL INTERACTIONS}

As communication is a complicated, cooperative process, if there is a breakdown in a communicative process it may lead to the impediment of a successful transfer of understanding among the people (Lunenburg, 2010). There can be multiple reasons for the failure of a communication process. Therefore, communicators need to take the feedback from the receiver to make sure that message has been communicated, and then the feedback of receiver may differ from your given idea which is not open-heartedly acceptable in our society. There is a general trend in our society that every person considers his or her, beliefs, opinion and thought superior to others and further wants that others should behave accordingly. Individuals or groups of all the social institutions have different levels of understanding which can capacitate a certain degree of dialogues or social interaction which may vary and differ with the existing ideas and beliefs. Five basic social institutions are political, educational, economic, family and religion. Here in this study researcher is focusing on three social institutions, family, and religion. The researcher tried to find out the communication barriers in these institutions and the process of feedback in social interaction. Generally, it prevails amongst a large segment of the population that understanding about their beliefs, faith, views, and thoughts are superior hence enforcing other to follow them and not allowing space to other thoughts, belief and dogma thus creating conflict amongst different groups. In families, parents are not allowing their kids to speak against their ideas they force them to obey their ideas and thoughts children have no right to give their personal and different opinion this is a general trend in Pakistani families. Mothers do not discuss the basic issues with her daughter who is important for her knowledge although the mother-daughter relationship is the closest relation on the earth. In sibling, sister is very reserved with her brother she does not share her social and personal issues with her brother if she does that it makes his brother offended and he took the serious reaction to this, whereas she is very much comfortable with her sister especially if she is the youngest one. Cooper, Grotevant, and Condon (1983) in their research examined the relationship between the individual disparities amongst the youths in their exploration of identities as well as the communication molds of their families.

Contrary to the customary concepts of youths as a time of breaking the parent-child link, the contemporary data endorses a viewpoint of that era as a continuing revision between the parents and their children from the unequal right through the adulthood. When children did not get chance to give their feedback to their elders in the family, they are doing their catharsis through different ways, they choose alternate ways for the flow of information about social media is a big of this. Same is happening at educational institutes students are not allowed to give a different opinion to a teacher they are not allowed to say his or her teacher that you have said wrong, or reality is otherwise. In the religious discussion, the same thing is happening. Mishal brutal and torture killing in the university campus and killing of two innocent boys in Sialkot on the pretext of religion are few examples of the recent past. Thus, suppressing the innovative stances and discouraging the concept of open debate on any novel idea or belief in society. This situation ultimately stops the people to engage in any kind of discussion due to an intolerant response from the society and hence a social blockade of sharing ideas and thoughts occurs. Resultantly, it leads towards the communication barrier and stops the process of feedback in social interaction. Feedback is an essential component of communication, thus enhancing the professional and personal development. This study will focus on the following elements of communication: (1) process of communication, (2) communication barrier, which hinders effective communication. Hence, the ultimate results of the research will help in devising effective communication and an enhanced mechanism of feedback.

\section{COMMUNICATION BARRIERS IN THE FAMILY SYSTEM}

Any family system deficient of healthy communication amongst its members is similar to a ship without a captain. With the aim to prevent any tragedy befalling on a family unit, it is important to comprehend the various barriers of communication in a family that occurs due to the misconceptions, the faulty course of interaction among the member of the family as well not giving due weight to the say of each member of the family. Hence, for healthy communication in the family without any unnecessary barriers, every member of the family should be paid attention, comprehended and respected (Jacobowski et al., 2010). Nevertheless, the issues in family communication arise in several manners. It could be as minor that some misunderstanding takes place between the members of the society, lack of trust and appreciation of the role of the members, as well, the parents unaware of the activities of their children who are quite often engaged in unhealthy activities. More important, they are usually a huge communication gap between the parents and their children as they seldom discuss their common problems with each other. Hence, in various instances, the members of a family may actively disengage themselves. Moreover, in many cases, the efficacy of strong family set up is eroded due to the neglect of the duties of the parents towards the family communication process.

\section{Understanding the Long-Term Impact}

The problems in family communication are usually due to psychological and interactive problems. Such problems also affect to a large community, for instance, the workplaces, at schools, and in other 
social environments due to the implementation of faulty communication styles in the society. As well, the individuals in the families work in unique ways, and their prime aim is to make their families happy and contented. Nevertheless, there exist discrete elements concerning the happiness of the family. However, one of the most significant aspects is the communication amongst the members of the families. The children, in particular, require robust and affirmative communication so that they develop characteristics and competencies to apply all over in their lives. Moreover, the ways wherein the people communicate with each other highly impact the families, and thus, poor communication, on the other hand, would produce negative results. Thus, the barriers caused due to poor communication could be displayed in various manners. For instance, shouting, censuring, applying the expressions like "always" or "never", swearwords, callingnames, concealing secrets, labelling an individual as "bad" bullying, or physically harming and cursing.

\section{Face-Saving}

When there are critical barriers to positive communication in the family, the children considered themselves beleaguered with threats or criticisms. They are judged or accused of something they believe is inaccurate or untrue for them. Consequently, their personality or confidence is constantly tested. As well, face-saving becomes a regular feature for them. The barriers in communication divert from the real issues to a secondary issue of the children "face". "face is the communicator's claim to be seen as a certain kind of person" (Folger, Poole, \& Stutman, 1997). In fact, "face-saving" is strongly related to link to a defensive approach since it supports the self-esteem of a person against the criticisms and censure. According to Goffman (1968) "face as the positive social value a person effectively claims for himself by the line others assume, he has taken during a particular contact" (p. 226). As well as Ting-Toomey (1988) stated. "face, in essence, is a projected image of one's self in a relational situation” (p. 215). Accordingly, if a negative account endangers the individual discernment of identity, the defensive approach is engaged by the individuals to defend, valid, or justify their behavior.

\section{Perceived Threats}

The individuals in the family could have perceived threats as a result of negative communication in the family. Indeed, they believed it did not make sense if the perceived threats or criticisms were factual or unreal. Thus, if the individuals perceive threats, the reaction could lead to defensive behaviors in them. Moreover, they assume they are going to be criticized or feel insecure somehow. As well, they may consider themselves being censured or blamed falsely.

\section{Protectionism}

The word "protection" refers to a protective mechanism for the survival of individuals in a family where there are barriers to positive communications. The censured individuals consider that their stance is customary when the families are at odds, and the trust levels amongst the members may be poor or non-existing. Thus, the individuals feel the necessity to safeguard their self-esteem or to protect themselves that they are anxious to either expose, lose or reveal. However, one arbiter believed it was important that people thought they had the authority to safeguard themselves.

\section{Defensive Behaviors}

The barriers to communication in families could lead to defensive behaviors that could be seen wholly or nonverbally. The background and kind of disagreements are significant causes in establishing the characteristics of defensive behavior. Accordingly, when the individuals in the family espouse defensive behavior, they deal with the circumstances through their distinctive outlooks, whether they are intimidated or wrongly indicted. Consequently, they communicate the outlooks through verbal and non-verbal manners. Besides, they react to the situation defensively in the following manners: (1) passive: to withdraw or isolate themselves, (2) aggressive: vocally or physically criticize or complain and accuse other, and (3) assertive: delineate clear limits and state what is required. Indeed, the individuals in the family who espoused defensive behaviors usually cannot have sympathy for or appreciate the point of view of others which is in disagreement from theirs. Besides, they are usually reluctant to accept new data or understand new perspectives. On the other hand, non-verbal defensive behavior might imply passive as well as aggressive elements. According to Fine, the classification of defensive behaviors has developed to "include virtually any dynamic process in which there is a way of warding off the anxiety" (Fine, 1979). He noted that there existed an ever-increasing list of defense approaches of problems, as plainly "anything can be used as a defense against something else" (Fine, 1979 p. 297). Nevertheless, the same principle could be applied to the observation of behaviors.

\section{Implementing Strategies to Improve Communication}

The parents in families are responsible for modelling excellent communication methods. Thus, when children realize that their parents communicate well, work dynamically to endorse each other vocally and non-vocally, they acquire communication skills to argue with each other positively. The analysts advocate that families should dine together at least three times a week to support healthy communication among them. The families following that rule have benefits when the children are involved in the communication-building procedure. As well, the children realize better academic success and improved psychological welfare.

\section{EDUCATIONAL INSTITUTES RESTRICT THE STUDENTS' POINT OF VIEWS/IDEAS}

Efficient interaction between teachers and the taught brings about the improvement in the learning environment as well as a positive milieu. Nevertheless, the communication between the two major stakeholders is successful when both fulfil their role constructively. The communication barriers between the teachers and the students indeed make it hard for the students to get the best from the teachers. Many times, the teachers are seen as unsuccessful to focus each of their students. As well, the students face the language or lecture which may cause difficulties for the students to grasp properly. Moreover, the disparities in personalities and peer pressure create poor communication in the educational environment of the institutes. Following the possible dynamics of poor communication between teachers and students.

\section{Unknown Expectations}

There are unknown expectations when both the teachers and the students remain silent on issues that should be discussed in detail in the 
class. The students at times assume they are consuming a lot of time of the teachers with constant communication in the classroom. On the other hand, the teachers consider that the students are disinterested in the studies or have no issues to deal with the lecture. Indeed, the teachers should lay out their expectations about the outcome of the lectures and the best methods of communication with the students.

\section{Problems with Comprehension}

Often, the students experience learning or speech problems and thus fail to communicate positively in classroom environments. As well, they might have problems in the comprehension of lessons and organization of their views. Due to their qualms, they usually remain silent as an of fear of isolation and embarrassment from the mainstream classmates. Indeed, the normally discuss with the students about their assignment and not the problematical elements of the assignment. Also, the efforts of the students to ask for help from the teachers cause adverse labelling from some teachers.

\section{Uninteresting Classroom Lessons}

Poor classroom communication occurs when the students get uninterested or unresponsive concerning their assignment. True, it is rather difficult for the teachers to engage the lessons interesting all over the period. They should have the skills to engage the student's motivation in the lessons through some relevant activities in the classrooms. For instance, challenging classwork, technology-driven discourses, and innovative assignments may motivate the students to have positive communication in the classroom. In contrast, the outmoded and dull classwork generate communication barriers, and students seek the classes to be ended.

\section{Personality Disparities}

The communication amongst teachers and students could also face difficulties due to personality disparities. For instance, a lot of students are uneasy about linking themselves on individual levels with their teachers and thus prevent interacting with them. That personality issue of students could be distressing for the teachers who always try to have a good relationship with them so get the best from them. Hence, those students who are extrovert and more outspoken usually are popular with the teachers. However, the teachers and the peers might get exasperated with the students who only want to draw attention. Thus, personality disparities between the teachers and the students could cause dissatisfaction, discontentment and a barrier of positive interaction between the teachers and students.

\section{Peer Pressure}

At times, "peer pressure" can also create communication barriers in the educational institutes when the students react to their tutors through humorous, casual or disconnected discussions. The teachers could deal with those students to have a positive communication milieu in the class by following the rules. (1) Encourage all the talks that are related to learning only, (2) convince the students that communication is an important aspect of their learning, (3) assist the students to develop ingenious and creative ways while seeking assistance and communicating positively in the classroom, and (4) discard the irrelevant and superficial discussion in the classrooms as well as avoid making needless presumptions considering the rationales underlying various questions. The research points out students feel less hassled in their examinations, discourses, personal matters and higher education. On the contrary, they are distressed when the teachers are ill-prepared for teaching the lessons and have poor communication within the school environment. As well, a harmful approach towards the students could result when the teachers consider the students a nuisance and unproductive. As a result, the students are expected to show attitude and restrict positive communication with the teachers. Similarly, if all communication with the teachers is negative, then the students would seek another avenue to get an education.

\section{Academic Freedom to Impart Knowledge}

An educational institution serves as a social place wherein discrete challenging statements to truth could be examined and evaluated, free from political intervention. The instructors should play a pivotal part in the dissemination of knowledge and have the professional responsibilities to impart for the quality education to the students in the educational institutes. Although other stakeholders play a key role in the administration of the educational institutes, the teachers, and the students are at the centerpiece of the educational system. To contribute quality education to the students, the teachers need the necessary independence to put into practice their educational philosophies they lead, that should be restricted by political, religious, or other maxims. Also, the teachers should face the knowledgeable disapproval of peers who stand for a wide range of understanding and skill to establish an organization of knowledge.

\section{Communicative Diversity and the Development of Judgment}

Through the people usually see that the teacher "impart knowledge" to students, the truth implies quality education, much time is dedicated to teaching students how to get new knowledge and how to apply it in the society. Thus, the teachers in educational institutes require academic independence to study their studies that could include disputed issues and real-world repercussions with the students. Accordingly, to assist the students to think cognitively and in a rational manner concerning a topic or issue, the teachers dedicate themselves critically what the students already understand or consider about the topic in hand and are engaged before understanding the newer one which modifies the old one. Thus, that process of promoting a quality education changes the mindsets of the students as well as of the teachers. Since knowledge is ever-expanding, its ultimate destination is undefined. Hence, to create critical judgments, the students as well need the liberty to vent their thoughts and views freely in addition to continual opportunities to evaluate and develop various discernments and outlooks. Thus, diversity in the educational environment is a vital process. The study points out that the students are more expected to create cognitive complexities when they constantly communicate with diverse people whose viewpoints and experiences are quite different from their viewpoints. However, the expression of ideas and sharing different outlooks concerning ethnicity, gender, religion, or racial beliefs, maybe rather troublesome for the students. Hence, they need a safe milieu to feel free and secure to utter their viewpoints.

\section{Violations}

The basic notion in various religions, due to their particular religious doctrines, has a "natural" inclination to become offenders. On the other hand, a similarly "natural" inclination results in as victims who indeed are incapable to solve the complicated socio-political and psychological issues of human rights that take place in various walks of life. Nevertheless, it occurs that specific religious groups whose members are persecuted terribly. Though in a few instances, it could be clearly distinguished between the offenders and the sufferers, in many 
instances, the application of such difference becomes complicated or completely impossible. Moreover, the victims may have a shocking past of religious oppression as well apply significant stress against the internal foes or rebels so as for maintaining unity in their ranks, and with the likely outcome of infringements of the basic rights of people. Besides, people should not ignore contemporary occurrences like women suffering as a result of "gender-based" marginalization from the religious society (Stuart, 2010).

In fact, the violations in a society usually occur from an enigmatic mixture of anxiety and disrespect. Indeed, there are two key sources of the different expressions of severe dislike that overwhelmingly impact several societies of the world. The combination of anxiety and disrespect seems illogical, as people usually are afraid of somebody considered more influential and hence rather superior, while the disrespect is generally the opposite aspect that people "look down" to those they hate. However, the combination appears to take place rather commonly. In mainstream society, it occurs that because of the two combinations of anxiety and disrespect can lead to hostilities, i.e., hostilities resulting from a feeling of defenselessness and the pretense of moral dominance. Thus, to overcome different infringements of religious freedom or faith necessitates difficult strategies for informal arbitration. Indeed, the mass media may play a significant part in imparting education and the elimination of frequent conflicts amongst different segments of society. However, a prerequisite of significant human rights actions is a clear understanding of theoretical issues as they occur in the domain of freedom of religion or beliefs.

\section{PROCESS OF COMMUNICATION FEEDBACK IN PAKISTANI FAMILY SYSTEMS}

One of the core principles of the family system in Pakistan is that it organizes itself to execute the day-to-day challenges and chores of life, in addition to accomplishing the evolving requirements of the family members. As well, critical to a family system in Pakistan is the notion of "holism" that considers the "family unit" as a group. Two Pakistani families residing at a street-side by side may communicate with each other although their past may be uniquely different. Nevertheless, by analyzing the families individually, the manner they communicate, their sense of humor, and their individuality are rather clouded. Each member of the Pakistani family creates patterns that make their lives realistic and adaptable. The communication between the family members shows a special pattern or affiliation that delineates and restricts the behaviors of family members over time and thus establishes a feeling of uniformity and harmony. The Pakistani families are "calibrated" using feedback systems to monitor and regulate the behaviors of the members according to certain rules. The family members may unite themselves into subsystems to realize the household tasks and targets of the family. However, when the household tasks assigned to the members become indistinct, the families are considered facing difficulties.

As regards the concept of holism, the Pakistani families outline certain limits between what should be included in the family system and what should be eliminated from it. The boundaries affect the movement of the members of the families into and out of the family system. Moreover, the boundaries control the communication pattern inside and outside of the family. Despite the fact, the notion of "boundaries" in the family system in Pakistan is mainly a symbolic form, the penetrability of the limits normally differentiates a family from the other. Indeed, some families have a large number of "boundaries" wherein the members of a family and others are permitted to move around freely, while some families experience strong limits on the movement of members of the family, and those accessing the family system in Pakistan. Furthermore, the limits control the communication pattern of a family. Hence, in more narrowed family units the rules stringently control what kind of communication may be taken place and with whom. On the other hand, in more interactive families the communication flows freely amongst the members of family freely move that have penetrable peripheries. The professionals counselling the families usually deal with families where they are the least barriers of communications. Indeed, such families provide the congenial environment where the ideas and advice of professionals are sincerely applied without any reservations. In contrast, in a reserved or closed society where there are communication barriers, the professionals experience difficult times being approved by the family. In such circumstances, the information concerning the family is rather hard to get, and notions and interventions of the professionals are faced with several oppositions. Moreover, it is vital to understand that communication barriers exist within the family system. Lastly, the penetrability in barriers in the family system would usually alter with the evolving era and requirement of the members of the family.

\section{NATURE OF COMMUNICATION FEEDBACK IN PAKISTANI EDUCATIONAL INSTITUTES}

The poor academic results of the students may be due to several dynamics. While examining the problem, it should be kept in mind that the role of teachers in the whole educational set up is vital. That is more so in Pakistan where the teachers are thought of as a key source of education for the students. Thus, communication in educational institutes is meaningful. So far, no particular research has been carried out about the use of positive communication aids in Pakistani educational institutes employed by the teachers and the students. Moreover, teachers who considered the feedback of students show their understanding of skills that correspond well with their thoughts, communicating in a friendly way, remembering the earlier thoughts selectively and unmistakably. As well, the students communicated their thoughts verbally and in-text successfully, clearly and in remarkable ways. Furthermore, the students offered feedback in critical expressions. Consequently, the teachers supposed that the knowledge of students was poor. Besides, the teachers considered the attention of students was not obtained and preserved by the use of mass media. As well, the teachers thought that students belonging to poor families were poor in their oral and writing communications.

\section{THE ALTERNATES FOR THE FLOW OF INFORMATION IN THE ABSENCE OF FEEDBACK}

The students in rural regions are poor performers in verbal evaluations. Thus, the teachers should contribute positively to the improvement of such students by providing them with proper guidance. As well, the teachers must adopt a uniform policy in the class without any bias towards a particular segment of the student. The students who were not good listeners in the class failed in 
comprehending the lectures of the teachers. That appalling condition should be remedied soon. As well, the teachers should try to make their lectures appealing and worth-attending using various components of multi-media. Dullness must be eliminated from the lectures of the teachers through picture books, graded exercises, and functional articles. Comparative studies between the public and private educational institutes should be carried out to understand the advantages and disadvantages of both the education system in the public and private sectors. That kind of research may be useful for the policymakers and directors of education to enhance the communication competencies of teachers and students.

The main objective of this paper is as follows: (1) analyze family, educational and religious communication barriers, (2) study the process of feedback in social institutions, and (3) explore the alternate flow of information in the absence of feedback.

The researchers attempted to find out answers to the following questions.

RQ1 What are the communication barriers in the family system?

RQ2 How educational institutes restrict the students' point of view/ideas?

RQ3 What is the process of communication feedback in Pakistani family systems?

RQ4 What is the nature of feedback in religious institutes?

RQ5 What is the nature of communication feedback in Pakistani educational institutes?

RQ6 What are the alternates for the flow of information in the absence of feedback?

\section{METHODOLOGY}

The qualitative research method was employed to achieve the objectives of the study. Keeping in view the nature and objectives of the study qualitative research method is employed for this research. For collecting qualitative data from the field structured questionnaires were developed for each target group and after pre-testing finalized the questionnaire and administered to the respondents.

The universe of the present research comprises of both genders belonging to different walks of life thus ensuring the representation of the wide range of individuals for increasing the generalizability of the findings. Keeping in view the limitations of researcher and time constraints, the target population for the present research is from the urban area of district Lahore. Population distribution is given as under:

1. Students - comprising of age group 15-35 years of both gender from different institutions.

2. Family Members - comprising of age group 15-35 years of both gender from different parts of the Lahore and varied social strata.

3. Religious Followers - comprising of age group 15-35 years of both genders from different sects and different areas of Lahore.

\section{Sample Size}

Stratified single-stage random sampling technique was used for this study. A stratified single-stage random sample of 20 respondents from each category of the above-mentioned groups was carefully drawn to get the maximum quality data. Researcher carefully us proportionately from both genders ensuring representation of both genders perceptions. Thus, a total of 60 respondents were interviewed during this study.

\section{Research Tools}

To collect qualitative data comprehensive research tools were developed for each group differently. Researchers adopted In-depth Interview (IDI) technique and developed a semi-structured questionnaire and checklist for each group differently, to get appropriate response from the respondents. After the selection of the sample, the researcher look appointment from each group members and collected data on the developed tools from each category of the respondent.

\section{Data Analysis}

After collection of the data respondent organized and transcribed and developed comparison tables and grading scale to analyze collected qualitative data. Result of the collected data is given in under the mentioned section.

\section{RESULTS AND INTERPRETATIONS}

\section{Families}

What is your family size?

The majority (67\%) of the respondent's family size including parents is seven members.

\section{What is your position number in a sibling?}

$30 \%$ of respondents are having the eldest position in the siblings with having 2 nd, 3 rd and 4 th position are $15 \%$ each remaining respondent were at 5 th to 7 th position in the family.

\section{Do you participate in your family discussions and decision making?}

Responding to this almost $85 \%$ of respondents said that they do not have the opportunity to discuss regularly with their parents. Those who are the eldest of the family are given some liberty to suggest their views only. However, majority $76 \%$ of them do not participate in any discussions with their parents. During interviews, respondents told that at times, they are given shut up call on expressing their views on personal issues and family issues.

\section{Does your family give importance to your suggestion and point of view?}

Due to the generation gap and depending upon their experience's parents do not consult/discuss any family related or other issues with their siblings expressed by $89 \%$ respondents. Moreover, its Taboo in society and considered bad that parents discuss family issues with their siblings.

Table 1. Distribution of populations

\begin{tabular}{|c|c|c|c|c|}
\hline No. & Respondents Categories & Male & Female & Total \\
\hline 1 & College and University Students & 10 & 10 & 20 \\
\hline 2 & Family Members & 10 & 10 & 20 \\
\hline \multirow[t]{2}{*}{3} & Religious Followers & 10 & 10 & 20 \\
\hline & Total & 30 & 30 & 60 \\
\hline
\end{tabular}


Can you make decisions for yourself?

$68 \%$ of the respondents are not given the liberty to make their own decisions. 30\% of the respondents said they take their own decisions and their family supports them in making their own choices. Majority of them are having the eldest position in the family who has the liberty to make their own decision.

Can you go against your family's point of view (which can be general, political, religious thoughts or any)?

It was rather inconceivable for the respondents to go against the views of the family headed by their parents. Even if they have a different idea or opinion, they said we don't want to go against our parents. Few respondents $20 \%$ said they often had a different point of view especially regarding politics but they remain unsuccessful to convince their families, according to them their parents are not ready to accept any new idea, they mind if child proposes any new or different idea. Parents are might be under social pressure that's why they don't accept any new thought or idea.

What are the communication barriers in your family system?

The family system is usually led by parents who have poor communication with their children. $70 \%$ of the respondents said that our parents are conservative, they don't accept modern ideas they want to stick with their stereotypical believes. $25 \%$ of the respondents claim this communication gap between Pakistani families is because of their culture, it can't be minimized. Only $5 \%$ feel there is no communication gap or barrier in their family system, they discuss all the issues and matters with each other without any hurdle.

\section{What is the process of communication feedback in your family?}

The respondents said they are rarely given communication feedback from their parents. They just keep silent over the views expressed by children. 55\% said they just listen the point of view of their elders and parents they are not allowed to argue if they try to give their opinion their elder gave them to shut up call and discourage them for having a different idea. Respondent feels isolated if give any different point of view.

Which medium do you use for your catharsis or the flow of information in the absence of feedback?

The absence of proper feedback at home causes the respondents to seek their close friends or social media to vent their views said by $80 \%$ of respondents. Ultimately, they have to give their feedback once it's not accepted by the sender or their parents. They give their feedback to the sibling or peer group and most to the time on social media especially on Facebook. Further, 30\% do their catharsis with their age fellows and with friend's chit chat.

\section{Educational Institutes}

Are you satisfied with your educational system?

The majority $80 \%$ of the students were dissatisfied with their educational system. 20\% were unresponsive for their educational system they were unable to judge this is fine or there is any problem with the educational system.

\section{What is the feedback process in your classroom?}

There exists no particular feedback process. The majority (74\%) of the teachers are not interested in giving feedback to their students because there is always a deep communication gap between the teachers and the taught. The teachers are more concerned about using the time to deliver their lectures and then to leave.

\section{Can you speak against your teacher's point of view?}

$66 \%$ of the students are afraid to pass a critical judgment of the opinions of the teachers. They could present their case meekly and humbly as not to incite their self-respect and to challenge their authority.

\section{Do you think educational institutes restrict the students' point of view/ideas?}

The majority (72\%) of the students believe their views are rather curtailed and did not reach their teachers as a result of a large communication gap that existed between the two.

\section{What are the reasons students don't give your point of view if it's different from your teacher?}

The students are usually hesitant about expressing their views or fear strong reprisals from the teachers in the form of derogatory and insulting remarks.

If you dare to give your idea in the classroom or disagree with your teacher's point of view then how does your teacher behave?

Some teachers (34\%) are willing to listen intently to the viewpoints of the students. However, the majority of the teachers disdain to listen to the suggestions of the students and thus, disregard the views of the students.

If you couldn't give feedback in your classroom then what are the alternates for feedback or the flow of information?

The students generally vent their feelings through their fellow students. At times, they discuss their friends, through social media outlooks or at times with their siblings.

Which medium do you use for your catharsis or the flow of information in the absence of feedback?

Responding to this question, the majority said in our society there is only one medium where they can express themselves freely without any inhabitations and that is social media. Few expressed that besides social media like-minded friends and peers are another opening for them to share their views.

\section{Are you satisfied with the overall communication flow at the institutes?}

The communication flow should be free and frank in educational environments. It is pathetic to see that there existed a wide communication gap between the teachers and taught which is not conducive for the healthy learning environment and the future of the students.

\section{Religion}

Where and with whom do you normally have religious communication?

The religious communication is usually done at the mosques or free time at home or in the educational institutes. At the religious places, like mosques, it is a convenience to hold discussions the learned scholars, namely the Moulana and Molvi are usually present as well with a large number of religious books present at the places. At home, if the parents have strong backgrounds, which are usually not, the religious ideas and issues are discussed with parents, or with those members of the family having some background of the religion. Now, with the popularity of social media, many issues are solving through Facebook or Google search engine as well. 


\section{Do you go to religious institutes?}

The majority of the male from the selected group attend prayers only on Fridays or on special events, for example, "Eid-ul-Fitr" and "Eid-ul-Adha". The female students hardly ever go to religious institutes, though at times they attend wedding ceremonies. Few regularly go to the religious institute not just for offering prayer but they also attend the lectures delivered by religious scholars they are even following the religious scholars on social media for gaining knowledge.

\section{Do you face any barrier during the religious discussion?}

There are some barriers during religious discussions in the presence of the elders when they interrupt the youths frequently and do not allow them to discuss freely on religious issues. This is said by respondents that because the elders believe that the youths have a scanty knowledge and they are ignored most often in the discussions.

\section{What is the nature of feedback in the religious institutes?}

The majority of the group of students believed there was no positive feedback from the religious institutes. The majority of the religious institutes are disinclined to take up social matters and provide a meaningful response.

\section{Can you give your point of view or share your thoughts at the religious} institute?

It is rather difficult to vent religious feelings and viewpoints in the religious institutes. The institutes do not believe in your views unless you are sporting beard or having caps on your heads. The dressings should be non-western i.e., wearing jeans and trousers and other western dresses. As well, the so-called institutes would look for some credentials from top religious academies and institutions to give you the freedom to give any religious verdict.

\section{How religious communication barrier abstain the followers from having} their own opinions?

The respondents said the tight and rigid atmosphere at the religious institutions could stifle religious opinions. The lack of religious knowledge as led to a large number of schools of thoughts, who are inflexible and rigid and are ill-prepared to listen to the views going against their orthodox beliefs.

\section{What are the reasons/causes to don't get follower point of view if it's} different?

The majority of religious institutes are funded by the people. They have a particular religious agenda to follow. The institutions are afraid not to lose their monopoly and influence amongst their sects. They accept the followers who are inclined towards their particular views and reject the views of those who do not match with the views of the mainstream.

\section{If someone dares to share his/her thoughts in religious communication} then how does religious scholar behave?

A limited number of religious scholars are liberal. They are sincere to help you when you need them. These scholars listen to your views intently and give you the right advice or correct you about the religious issues. However, in contrast, a large number of them consider they are an authority on religion because the general people lack the very basic knowledge of religion. Respondents said that these types of scholars do not allow you to talk freely about religion.
If you couldn't share your thoughts or give feedback at religious institute then what are the alternates for feedback?

Majority of the respondents feel to get feedback from those attending the religious institutes who are liberal and willing to discuss with them easily and comfortably. At home, they can have feedbacks from their parents. As well, they can have feedbacks from their friends, or by browsing the internet, especially through social media.

Which medium do you use for your catharsis or the flow of information in the absence of feedback?

The respondents said they are hooked to Facebook, Instagram, WhatsApp, and other social media in the absence of any positive feedback from the religious institutes.

\section{DISCUSSION}

Freedom of speech and expression is of significance for the liberty and right of independent people and nations. The freedom of thought and expression is a cornerstone of the "source of the expression". Besides, in the contemporary world, the freedom to speak and express is vital for the democratic world, if done healthily, without breaking the fundamental rights and infringement of the social fabric of the society. Further, freedom of expression and speech is a vital block through which people could fulfil their identities. It gains ascendancy while the rulers vie for the welfare state is based on equality, justice and fair play in all domains of the society. Hence, the freedom of speech and expression are considered vital blocks of freedom in a sovereign, and welfare country.

Furthermore, the society without freedom of speech and expression, rationale for a reason could not be accomplished. As well, without the vital freedom, society is not expected to be high in the scholarly sense, either it could be in the case of an individual or the whole society. Besides, democracy in a country could be flourished through rational discussion and the ensuing government would only strong and popular when people are given the freedom to actively vent their views on different matters of its administration. Consequently, people must be adequately educated to have their rights accomplished through the laws of the country. Moreover, the freedom of the speech and expression is vital since the censorial power of the country is embedded in the masses and thus should not be used against them. Also, the important aspect of freedom of speech and expression is that the people should be as a means as they are an end to them as well as others.

\section{Advantages of Free Speech and Expression}

Free speech and expression give rise to fantastic ideas and through that are indispensable for the growth of welfare society. The objective of private thoughts is meant to gain influences as well as to shape public tendencies and behaviors towards specific behaviors or sentiments. It could be harmful to the members of the society that the positive views of the people are stifled and curbed, and the development of the society is brought to a standstill. Indeed, the suppression of speech and expression could lead to the sterilization of a society. Moreover, the social interest doctrine suggests that the free expression is founded on the idea that without expression of free speech and expression it is inconceivable for a society to prosper since free communication is vital for a prosperous society. The fundaments goals and objectives of free speech and express are based on the following ideals. Freedom of speech and expression is required to fulfil the following objectives. 


\section{The discovery of truth}

Generally, the most potent claim for the principle of free speech is related to the significance of open discussion among people or individuals to discover the truth. Hence, if there are no restrictions on speech and expression among the people, society would benefit from the accurate facts and data as well as valuable opinions. The positive and constructive discussion freely done could lead to a healthy society that should be free bigotry and narrow-mindedness among the people. Moreover, the best outcome of open views would be the trust of the people on themselves as well in society. The truth that evolves through liberal discussions and expression of ideas would be a vital platform of "free trade in ideas" and a significant bank of "intellectual think-tank".

\section{Self-Satisfaction}

Another significant aspect of free speech and expression is that it proves an essential part of people for their self-growth and fulfilment of their objective goals. Indeed, the constraints put by various agencies curb the natural tendencies of their personalities and development. As well, the philosophical thinking, conscious decisions and the prospects for self-development, discriminates vividly of human beings from the animals. Moreover, freedom of speech and expression is inextricably related to other vital freedoms in society. Hence, there should be definitive freedom of speech and expression that could be beneficially for the whole society.

\section{Democratic Value}

Freedom of speech and expression is the essential aspect of a democratic regime. The people must be provided with a complete environment that is conducive to act and express freely under the definite norms of the society. Indeed, the freedom of speech and expression is an essential block to the smooth running of the democratic elements of a country. Accordingly, these are considered as the first precondition of freedom. Moreover, it holds a unique place in the echelons of the hierarchy of freedom that support and protect different aspects of freedoms. Hence, it is rightly stated that "freedom of speech and expression" it is the mother of all other freedoms. Furthermore, in a popular regime, the "freedom of speech and expression" give rise to avenues of free discussion of issues among the masses. It contributes significantly to the creation of positive public opinions on almost all walks of the society, namely socio-political and economic issues at hand.

\section{To ensure pluralism}

The "freedom of speech and expression" strengthen pluralism in society. As well, it ensures that various lifestyles are legalized and the promotion of the self-esteem of a segment of people who follow a particular lifestyle. However, various constitutional aspects have decreed that the free speech of media could guarantee that the constitutional pluralism is protected. Thus, it can be argued that "freedom of speech and expression" facilitates the identification of truth that should be critical for the smooth working of a regime and could be an important means of self-fulfillment and freedom for the people in the society. As well, it is in the interest of the members of the society to disseminate ideas and data in a positive way that could not only be beneficial to them but also the society at large.

\section{CONCLUSION}

Communication is a key to successful operation in social life. The researchers are clear that frank, open and frequent communication is a vital block of cohesion and a strong, healthy society. In addition, the society that possesses such characteristics work in unison with all the stakeholders in healthy ways and are strongly capable of resolving dayto-day problems faced by them. The overall data presented in the report implies that there is a strong relationship between societies. Without which the society is incapable to resolve most of their issues amicably and satisfyingly. Moreover, the data showed in the report that there exists a large communication gap in Pakistani society, whether it is in the domain of family, educational institutes, or religious institutes. All the stakeholders, especially, the parents, teachers and the mass media can create positive awareness amongst the masses to curb the menace of growing communication gap in the society.

The result of this research report may have significant implications for all the members of the society who are concerned with the growing communication gaps in society. In an independent, developing country, like Pakistan, it depicts a sorry state to see that the majority of the people face the menace of communication gap which is vital for a healthy and vibrant society. There is a high need to curb this menace by seeking positive solutions, like educating people and following the model of the true Islamic welfare state, wherein everyone is given his/her due share in the society. As well, the rights of the people should be safeguarded, and justice and equity should prevail.

\section{Media as a Source of Expression}

The freedom of speech and expression is vital for the communication of opinions, concepts, philosophy, and other deliberative activities. Indeed, the communication of positive thoughts and philosophies unify society together and make it coherent and healthy. Thus, for a sound and healthy society, there must exist free flow of communication of ideas and freedom of media outlets. Every individual in a society is a means of communication and expression. Through media outlets, people are facilitated to reach others individually and institutionally. The media outlets are the most significant provider and communication means all over the world for "freedom of speech and expression". Accordingly, the mass media holds the professional responsibility to disseminate true, unbiased and precise news information to the viewers and audience. As well, the news should be beneficial for the public good and provide the news with great scrutiny and fairness, irrespective of discrimination and biases.

\section{Responsibility of Media}

The core rational purpose of the mass media is to provide untainted news without provocative production, freely and at a precise time. Moreover, the mass media should carry out its duties by the social values of society. True, it is intrinsic in innate human minds to interact, to discuss ideas, and to understand the changes in the surroundings so that to know the truth. Thus. the mass media contributes to highlight the facts and enlighten the people through unbiased. unambiguous and factual reporting.

\section{Right to Expression Beyond National Boundaries}

The right to "freedom of speech and expression" crosses the national boundaries. The great revolution in the 21 st century has radicalized the mass media and has shattered all the boundaries to reach 
the people. As well, the mass media has facilitated the communication of information and news to any corner of the world in a jiff. The modern technology of the internet has made the world small and easily accessible to all people. Hence, modern technology has made it possible the point that everyone in this world should have the right to full freedom of viewpoints and expression. The rights should include freedom to opinions and expression without interference. As well, the people should have complete freedom to seek, receive and report information through the mass media irrespective of any frontier.

\section{LIMITATION AND FUTURE RESEARCH DIRECTIONS}

One of the major constraints faced during the study was respondent's inhibition in expressing factual responses, the baggage of old traditions and culture in this changing environment dragged responses on social and moral grounds with the baggage of traditions and culture. Hence researcher had to dig while focusing on the social institution, "education" academia representative can be offended. Researcher intentionally took the parent and children from different families to gather better results. Mobility issues were also one of the issues faced due to limited resources and time. Due to exploratory study/research especially after the rapid growth of social media, there is negligible earlier work on the topic thus researcher has to present and develop new communication feedback model, wherein receiver instead of giving feedback to the sender is expressing his sentiments/views before the different group and on a different medium.

It looks like barrier-free communication is impossible to happen in future. However, communication barriers could be slashed significantly. Firstly, people should constantly endeavor to enhance the messages they dispatch. Secondly, people should constantly endeavor to enhance their perception of the messages they receive. Thus, people should not only strive to be understood but also, they try to understand in a society. Moreover, communicative feedback is vital in creating professional growth and generally advanced in society. Besides, it offers people with data on their past performances so that future performance could be enhanced. Without positive feedback, good performance is not possible, and the issues about professional competence continued unabated. As regards modern changes in technologies, people should strive hard to provide quality feedback to improve communication. Given the complexity of modern education, there is a need for improved understanding of the processes of communication and applying feedback as a base for enhanced development towards expressive assessment.

Author contributions: All authors were involved in concept, design, collection of data, interpretation, writing, and critically revising the article. All authors approve final version of the article.

Funding: The authors received no financial support for the research and/or authorship of this article.

Declaration of interest: Authors declare no competing interest.
Data availability: Data generated or analysed during this study are available from the authors on request.

\section{REFERENCES}

Ajmera, R. (2018). The Effects of Poor Communication. oureverydaylife. https://oureverydaylife.com/the-effects-of-poor-communication4232594.html

Cooper, C. R, Grotevant, H. D. \& Condon, S. M. (1983). Individuality and connectedness in the family as a context for adolescent identity formation and role-taking skill. New Directions for Child Development, 1983(22), 43-59. https://doi.org/10.1002/ cd.23219832205

Donaldson, R. L. (2011). Student acceptance of mobile learning (Doctoral dissertation), Florida State University. http://etd.lib.fsu.edu/ theses/available/etd05312011-074842/unrestricted/Donaldson_R _dissertation_2011.pdf

Driscoll, A., \& Nagel, N.G. (2014). Family Socialization. Education.com.

Fine, R. (1979). A history of psychoanalysis. Columbia University Press.

Folger, J. P., Poole, M. S., \& Stutman, R. K. (1997). Working through conflict:Strategies for relationships, groups, and organizations (3rd. Ed.). Addison Westley.

Goffman, E. (1968). On face-work: An analysis of ritual elements in social interaction. In W. G. Bennis, E. H. Schein, R. L. Steele, D. E. Berlew (Eds.), Interpersonal dynamics, essays and readings on human interaction (Rev. ed., pp. 226-249). Dorsey Press.

İşman, A., Dabaj, F., Altinay, F., \& Altinay, Z. (2003). Communication Barriers in Distance Education. The Turkish Online Journal of Educational Technology, 2(4), Article 2.

Jacobowski, N. L. Girard, T. D., Mulder, J. A., \& Ely. E. W. (2010). Communication in critical care: family rounds in the intensive care unit. American Journal of Critical Care, 19(5), 421-430. https://cdoi.org/10.4037/ajcc2010656

Keyton, J. (2011). Communication and organizational culture. A key to understanding work experience. Sage.

Lunenburg, F. C. (2010). Communication: The process, barriers, and improving effectiveness, Schooling, 1(1), 1-11.

Lutgen-Sandvik, P. (2010). Destructive organizational communication: Processes, consequences, and constructive ways of organizing. Routledge. https://doi.org/10.4324/9780203928554

Stuart, A. (2010). Freedom of Religion and Gender Equality: Inclusive or Exclusive? Human Rights Law Review, 10(3), 429-459. https://doi.org/10.1093/hrlr/ngq014

Ting-Toomey, S. (1988). Intercultural conflict styles: A facenegotiation theory. In Y. Kim \& W. Gudykunst (Eds.), Theories in intercultural communication (pp. 213-235). Sage.

Yate, M. (2009). Hiring the best: A manager's guide to effective interviewing and recruiting. F \& W Media. 